\title{
PERCEIVED LEADERSHIP STYLES AND SME PERFORMANCE IN GHANA: ORGANIZATIONAL CULTURE AS A MEDIATOR?
}

\author{
Daniel Okofo-Darteh Jnr., University of Professional Studies Accra, Ghana \\ Alfred Amartei-Kwei, University of Professional Studies Accra, Ghana \\ Simon Owusu Boahen, Zhengzhou University, China
}

dx.doi.org/10.18374/JABE-20-1.4

\begin{abstract}
Following countless research work seeking to ascertain the nexus between organizational culture and performance, empirical findings seem inconclusive. The study attempted to ascertain the mediating role of enterprise culture on the influence of the perceived leadership styles on firm performance among Ghanaian SMEs in Accra Ghana. One hundred and forty-one (141) respondents were conveniently sampled from selected SMEs in the various sectors in Ghana for the study. All selected participants completed the multifactor leadership questionnaire (MLQ), organizational culture survey (OCS) and Organizational Performance Survey (OPS) at the same time. The data gathered was analyzed using Hayes' Process macro procedure in SPSS. The results revealed that organizational culture failed to play a significant mediating role in the influence of the perceived leadership styles on SME performance at 95\% confidence interval.
\end{abstract}

Keywords: Small and Medium Size Business, Organizational culture, Perceived Leadership Styles, Organizational Performance, Ga East District, Ghana. 